\title{
Capacity development through the sharing of climate information with diverse user communities
}

\author{
Gilma Mantilla ${ }^{1,2}$, Cynthia Thomson ${ }^{2 *}$, Jessica Sharoff ${ }^{2}$ Anthony G Barnston ${ }^{2}$ and Ashley Curtis ${ }^{2}$
}

\begin{abstract}
The International Research Institute for Climate and Society (IRI) is a premier global research and capacity development institution focused on enhancing society's capability to understand, use, manage and evaluate climate information. Its goal is to strengthen the technical capacity of individuals and organizations in order to increase the demand for climate information and its application.

In the early years of IRI, staff trained local meteorologists and decision makers, often in developing countries, on using information products that IRI's forecast group judged would be of value. However, in the last decade, IRI's approach to training has evolved into one that is more user-driven. Today, users are brought on board during the development of training curricula to learn what information and methodologies would be most useful for their local needs. This establishes a sense of trust and ownership in the training process. Approaches are tailored to different contexts and communities, and focus is placed on cultivating long-lasting partnerships.

The work presented in this article demonstrates the evolution of IRI's capacity building and development processes. It highlights how the IRI implements capacity development activities, with a particular emphasis on the early engagement of practitioners and end users. Numerous examples are provided of the successes related to knowledge gains and to the concrete applications of climate information that can occur when the design and implementation of activities are preformed in an integrative manner. This approach builds channels for interaction among practitioners, policymakers, scientists and other societal decision making groups. Though it has seen numerous successes, the IRI is continually evaluating its capacity development methods and looking for ways to improve upon them.
\end{abstract}

Keywords: Capacity building; Capacity development; Climate; Public health; Index insurance; Training; Education; End users; Outreach; Communication; Collaboration

\section{Background}

The proverb, "give a man a fish and you feed him for a day; teach a man to fish and you feed him for a lifetime" is perhaps the most famous iteration of what it means to build capacity. Since its inception, the International Research Institute for Climate and Society (IRI) has adopted and, as needed, made adjustments to this philosophy when it comes to enhancing society's capability to understand, use and manage climate information.

\footnotetext{
* Correspondence: cthomson@iri.columbia.edu

${ }^{2}$ The International Research Institute for Climate and Society (IRI), The Earth Institute, Columbia University, Lamont Campus, 61 Route 9, Monell Building, Palisades, NY 10964-8000, USA

Full list of author information is available at the end of the article
}

In the early years, IRI focused capacity building efforts on trainings, conducted with the idea that the institution's valuable climate monitoring and prediction knowledge would be helpful to pass on to meteorologists, climatologists and decision makers in targeted countries and regions. The early trainings tended to present local meteorologists and other users of climate information with products that the IRI forecast group identified as being of value. These sessions often culminated in the development of a consensus probability forecast for rainfall for the coming three-month period for the region in which the training was held. However, this approach was less about teaching how to fish than it was about showing how we fish.

\section{实 Springer}


After several years, it became clear that there was not as much end user uptake as expected, particularly in the agriculture and disaster management sectors. Despite not having an objectively based forecast of their own, end users were not significantly utilizing IRI's forecast products. We believe that three main factors were at play. First, the users were not involved in deciding what forecast products the IRI was presenting to them. Second, many end users were not familiar with the climate science or the IRI trainers themselves, making it difficult to have confidence in them or their products. Third, providing users with products, though beneficial, is not enough. Users need to understand how these products work and how best to utilize them.

IRI learned from these experiences, and over the last decade has transitioned from an institution that focuses on capacity building to one that focuses on capacity development. Rather than simply providing climate information and teaching users how to use it, we now work with them to address their specific needs and work to build a knowledge partnership that benefits both parties. Approaches are tailored to different contexts and communities, and focus is placed on cultivating a sense of user ownership in the process. This system has helped to maintain a two-way dialogue with end users and to clearly identify what information matters most to decision makers, which in turn has influenced IRI's own scientific research direction. Bringing users into the initial and subsequent discussions has also cultivated a greater sense of trust between IRI and the organizations and individuals it works with. This has enabled long-lasting partnerships that have led to better tailoring and reception of IRI's knowledge, data, information, tools and products, as well as enhanced the application of this information towards decision making.

This article describes four examples that showcase both the unified use of the approach described above and the ways it has been tailored to different end users: climate training for meteorological agencies; Masters-level education at Columbia University; facilitating connections between the public health and climate communities; and insuring the world's poorest farmers. These capacity development activities illustrate the range of contexts in which IRI is committed to transferring its knowledge through training and educational processes. This information is typically exchanged in-person--via workshops and classes, for example-and through online courses and web-based resources to expand the basis for learning about climate change, climate variability and climate risk management for decision making. This process is applied to key development sectors such as agriculture, public health, disasters and water resources. In this way, IRI produces a larger cadre of trainers pursuing positive outcomes in today's increasingly climate-sensitive world.
Training in the use of climate information and forecasts A foundational part of capacity development for climate adaptation and resilience is training users on the principles of the physical climate itself, including its observed variability and prediction. Such training involves the fundamental climate science that explains how predictions of short- or longer-term climate fluctuations or trends are possible. It also provides knowledge of how statistics can be used to represent some climate processes in order to develop skillful climate forecasts without having to run large dynamical prediction models on expensive computer systems, which is a major impediment to climate prediction in developing countries.

The IRI has conducted training in climate science and forecasting since its inception in the 1990s. Many of the early trainings were short-term workshops provided in association with regional Climate Outlook Forums or stand-alone trainings. These trainings emphasized the capability to predict seasonal climate due to influences such as the El Niño-Southern Oscillation in the tropical Pacific Ocean (Mason et al. 1999) or sea surface temperature patterns in other oceans. The final forecast product produced was usually presented as a set of probabilities for below-, near-, or above-normal rainfall over the coming threemonth period for the region.

Over time, trainings became increasingly tailored to the expressed specific needs of the training recipients, many of which were not interested in only a forecast of total seasonal rainfall but rather more detailed, regionspecific features such as the onset of the wet season or the frequency of dry spells during important growing seasons. IRI trainers became progressively more responsive to user demands and less wedded to their own judged "best products", learning that this two-way communication created more trust and subsequent uptake and beneficial use of climate information. This change in approach represents a transition from capacity building to capacity development.

A software tool created at IRI in the early 2000s, called the Climate Predictability Tool (CPT), was developed specifically with end user needs and knowledge in mind. CPT is freely available for download through IRI's website (The downloadable Climate Predictability Tool) and requires very little disk space or computing resources. Each revision to it has been based on extensive user feedback, leading to progressively better-developed versions and, consequently, encouraging greater collaboration within various climate-sensitive disciplines. CPT's flexible forecast formats allow products to be better tailored to user needs that vary regionally. Such tailoring makes forecasts easier to understand and use.

CPT has been a major part of numerous climate prediction trainings led worldwide by IRI, partners and interested parties over the last 10 years. These trainings 
are often aimed at hydro-meteorological offices in developing countries. IRI trainers typically stay in touch with trainees following a CPT training, often answering questions regarding the application of the tool to local data sets that were not available during the training session.

These trainings have helped cement CPT as an invaluable addition to the suite of tools typically used by hydrometeorological agencies in a number of countries and is used to make their routine real-time climate forecasts. In some cases, CPT has replaced more subjective forecasting methods, leading to increased forecast skill and more informative narratives accompanying the forecasts. These systematic improvements in issued forecast information have resulted in an increment in credibility to the decision makers and end users, which in turn has increased demand for the information. This general result has been evidenced in a number of countries-particularly in Africa, Central America and South America.

The trainings that include CPT bring together three important aspects of capacity development: increased knowledge and understanding of the climate system; increased ability to implement this greater knowledge into operational use-routinely providing the highest quality forecasts possible; and the inclusion on end users from the beginning of the process. Many developing countries do not have the resources needed to develop and run their own comprehensive dynamical climate model. However, they can download CPT and use it to statistically downscale state-of-the-art dynamical model forecasts produced outside their country.

Having more knowledgeable climatologists and higher quality forecasts in developing countries would be expected to lead to greater uptake of climate information by their governments and other sectors of their societies. For such improved forecasts, their greater use in decision making can increase a country's adaptation capacity and social and economic resilience. This scenario has been borne out in Ethiopia (Korecha \& Barnston 2007), Costa Rica and Panama, which have added CPT to their set of tools for making their routine climate forecasts and have requested additional trainings. The sequence of events (better forecasts, increased forecast credibility, increased forecast demand and use, and finally greater economic resilience) is what the IRI has been working to enhance over the last 15 years. The user-focused trainings and enabling steps are essential to such capacity development, and therefore trainings with continually advancing climate science knowledge, progressively enhanced versions of $\mathrm{CPT}$ and the creation of new tools are expected to continue.

\section{Training through formal education}

Climate forecasts, data and information can play a crucial role in how societies deal with climate risks.
However, the path to taking those products and applying them can be a murky one. IRI recognized the need for guides to help scientists, policymakers and communities navigate the path and in 2004 partnered with the Earth Institute and Columbia University to create the M.A. Program in Climate and Society.

Since its inception, the M.A. Program in Climate and Society has graduated more than 200 climate science and policy experts. Graduates share some commonalities when they enter and when they leave, but overall the program attracts students from around the world with a diverse array of backgrounds and skill sets.

These wide-ranging backgrounds are a large part of what makes the program unique. It allows both students and professors to address climate and its impacts from many different angles. Over half of the students from the most recent classes have been international. The program has had students who come directly from their undergraduate degrees as well as students who have been in the workforce. Students' backgrounds have included photography, finance, geography, environmental sciences, engineering, atmospheric sciences, music and even fashion design.

Five IRI scientists form the core faculty for the program along with two other researchers from Columbia. Together, they teach four core curriculum classes: Dynamics of Climate Variability and Change; Regional Dynamics, Climate and Climate Impacts; Quantitative Models of Climate-Sensitive Natural and Human Systems; and Managing Climate Variability and Adapting to Climate Change.

Through the two climate dynamics classes, students get an in-depth overview of the climate system both globally and regionally and the dynamics at play within the system. In the quantitative class, students further their quantitative skills using data sets, statistical tools and decision models to better understand the relation between climate and society. The final core class focuses on the societal aspect of climate and how to use risks analysis frameworks to assess and manage the impacts of climate risk, reduce the risk perception gap between scientists and the public, and use tools to communicate climate risk effectively.

Students also take five elective courses of their own choosing. Each student picks a set of elective courses from well-established programs across Columbia University based on their specific interests. The flexibility allows students to tailor the degree to focus on a sector, region or topic in which they are most interested. This mix of core classes and student-chosen electives gives graduates of the program the skills they need to understand climate science and the policy arena and act as conduits between scientist, policymakers, the public, and other climate information end-users. 
The curriculum concludes with an internship or thesis over the summer semester. A number of students complete this with the guidance of IRI scientists who provide mentorship while also giving students the opportunity to apply their new skills to a specific project. Again, internships and thesis topics are at the discretion of the students, so the experience they gain is valuable in preparing them for the next steps in their career.

Graduates of the M.A. in Climate and Society can be found throughout the world working in a variety of climate-related fields. Alumni of the program work in large international organizations such as the United Nations, the World Bank and the International Federation of the Red Cross/Red Crescent as well as in academia, the government, local NGOs, the private sector and at IRI itself. In each of these organizations, alumni are working to help society better understand and cope with the impacts of climate.

\section{Training on the use of climate information for public health professionals}

In addition to broad training efforts around climate, IRI has also helped boost the capacity development of specific sectors to understand how climate affects them and how to use climate information to adapt to specific problems. Public health is a sector where IRI has been deeply involved in training new leaders to champion the use of climate information.

The IRI course on Climate Information for Public Health $(\mathrm{CIPH})$ and its associated courses grew out of a recognition that there are major gaps in the knowledge, methodologies, tools, data and resources available to members of the public health community in their quest to better manage climate-related risks to improve public health outcomes. These gaps include a lack of educational and practitioner texts, tools, methodologies and data that illustrate the value of climate information to the public health sector (Connor et al. 2010).

$\mathrm{CIPH}$ is a unique two-week training course that offers public health practitioners, epidemiologists, policy makers, researchers, climate and meteorology professionals from around the world the opportunity to understand the role climate plays in driving the infectious disease burden and other public health outcomes. More importantly, it also provides the chance to learn practical methods for integrating climate knowledge into decision-making processes through expert lectures, focused discussions, practical exercises and participant projects. These activities show public health and climate professionals how to appropriately use and interpret climate information for their own institution, country and/ or region.

The first course was held on Columbia University's Lamont-Doherty campus in Palisades, New York in 2008 and involved 12 participants from around the world. The curriculum developed for this course, and ones that followed, has been heavily oriented toward methodology, data gathering and using evidence for decision making. This allows trainees to acquire in-depth knowledge and skills in decision making for healthcare planning of climate-sensitive diseases. There are three different modules: Basic Concepts in Public Health and Climate; Sources and Tools for Analyzing Climate and Public Health Data; and Climate Information in DecisionMaking for Climate-Sensitive Diseases. The IRI Data Library is used to support the CIPH training courses (Del Corral et al. 2012). The course also includes an entire evaluation process with questions addressing the design and delivery of the course as well as the opportunities for collaboration that could arise from the course (Cibrelus \& Mantilla 2009; Mantilla et al. 2010; Lowe et al. 2010).

Since 2008, the CIPH alumni network has grown to more than 140 practitioners from more than 25 countries. Based on the responses from those alumni and demand from other members of the climate and public health communities, the CIPH team decided in 2009 to take the course from Columbia University's Lamont campus to other countries and regions, and further tailor trainings to local needs and languages. CIPH has run courses in Ethiopia, Madagascar and Colombia (Teka et al. 2009; Cibrelus et al. 2010) and two regional courses in the Mercosur and Andean regions of Latin America $^{\mathrm{a}}$. Decisions relating to planning, preparation, implementation and evaluation of these and other $\mathrm{CIPH}$ courses are made collaboratively with local and regional alumni, partners and sponsors (Mantilla et al. 2011; Mantilla \& Lustig 2012).

Running these courses abroad has provided key insights into how to strengthen each subsequent course. $\mathrm{CIPH}$ organizers and trainers have learned that involving government climate and public health professionals as well as academic institutions from each country or region is an effective way to build critical mass on climate and public health related issues. The team has also learned the importance of enhancing the course, for example, by including a new module on proposal development and aligning this with a seed project initiative. The seed projects aimed to strengthen the creation of regional networks of cooperation and to help trainees apply the knowledge and tools provided by the course on practical projects addressing climate and health issues relevant to the participating countries. Six regional teams, each working on a different seed project to strengthen regional networks of cooperation and apply the knowledge and tools provided by the CIPH course, came out of the training courses in Latin America. For example, groups out of the Mercosur training are working on the following projects: a) Strengthening technical 
and scientific capabilities of Ecuador, Panama and Peru for the development of applications in climate and health; b) Climate variability and its likely impact on the health in Buenos Aires, Santiago, Montevideo, Salto and Manaus; and c) Diagnostic performances of diseases related to climate variability on the border between Brazil and Uruguay.

In addition to seed projects, CIPH alumni stay connected through a quarterly newsletter available in English, French and Spanish (CHIPH Newsletter), a best practices manual (Cibrelus \& Mantilla 2010) and a webbased platform to support the Climate Information for Public Health Action Network, which has more than 200 active members around the globe (Climate information for Public Health Action Network). Alumni of the course have also created various mechanisms to transfer their climate and public health knowledge at global and local levels. For example, one $2008 \mathrm{CIPH}$ alumna launched the Environmental Health Symposium in 2009 under the umbrella of the Annual Meeting of the American Meteorological Society using the knowledge she gathered throughout the CIPH course. This initiative currently runs annually, allowing other $\mathrm{CIPH}$ alumni to present their projects on climate and health and engaging other practitioners in the health and climate fields. CIPH also aims to reach more participants by encouraging past participants to hold their own CIPH courses as Ethiopian and Colombian alumni have done. By involving alumni in the design and dissemination of CIPH materials, and by creating online resources it is hoped that a wider audience can be reached.

\section{Training through collaborative processes tailored to meet farmers' needs}

There is a growing demand for innovative approaches to managing climate risk, to help reduce poverty and to meet the challenges of climate variability and change. Index insurance is a potential tool for both lessening the impacts of climate shocks and enabling investment and growth in the agriculture sector (Schwank et al. 2010) (Hazell et al. 2010). Index insurance provides farmers with insurance coverage based on an index-such as wind speed or an amount of rain during a certain window of time. Payouts are triggered when the index falls above or below a pre-specified threshold during crucial times of the season, and are not based on crop outputs explicitly (like traditional "indemnity" insurance). This can help resolve a number of fundamental problems that often make traditional crop insurance unworkable in rural parts of developing countries (Bank 2011). In principle, index-based products might lower an insurance company's transaction costs and risks, potentially reducing premiums for farmers and increasing accessibility. While there are significant challenges in applying this tool, because of its benefits many look to it as the first opportunity to bring agricultural insurance to many vulnerable populations.

It is hoped that index insurance can be specifically designed to help diminish the impacts that weather and climate extremes can have on lives and livelihoods (Hazell et al. 2010). By integrating insurance into a broader set of development tools it might be used to help farmers reduce their climate risk enough so they could take better advantage of opportunities that have the potential to substantially increase their income and help them adapt (Schwank et al. 2010).

For almost a decade, IRI has played a leading role in developing rainfall-indexing approaches in Africa, Asia and Central America. IRI's role goes beyond just creating indices. Given that it is a relatively new tool, there have been enormous gaps in applying index insurance for climate risk management and development. Developing the capacity of in-region stakeholders has been a key part of these efforts, in particular creating a foundation for collaboration and information sharing between project partners, local experts and farmers so that indices can be designed and better tailored to address specific risks.

IRI's index insurance capacity development process was originally developed to meet emerging demands in the $\mathrm{R} 42^{\mathrm{b}}$ Ethiopia ${ }^{\mathrm{c}}$ project, formerly known as the Horn of Africa Risk Transfer for Adaptation (HARITA) project. R4 Ethiopia is a climate change resiliency and development project that focuses on designing a scalable risk management package for low-income farmers in Ethiopia, including weather index insurance based on satellite rainfall data (Oxfam 2013). The lead partners on the project are Oxfam America (OA) and the local NGO, the Relief Society of Tigray (REST). Additional stakeholders include individual farmers as well as existing farmer organizations, community groups, research institutions, national and international financial institutions, government institutions and Ethiopia's National Meteorological Agency (NMA).

When IRI first became involved in the project during the exploratory phase in 2007, there was a strong focus on developing indices using detailed seasonal crop models based on IRI's data library, and looking at how seasonal climate variability affected agricultural outcomes. However, it quickly became apparent that this approach would not work because the product would not meet user needs or be of sufficient reliability in the real world. There was a need to invert the design process, incorporating local expert and end user feedback very early on in order to develop a more targeted, flexible, and valuable index product. The farmers, local experts and scientists needed to be directly linked to end up with a product that could address farmers' problems, based on solid science. 
In order for local stakeholders to provide valuable information and feedback regarding the development and design of potential indices and how these might tie in with other local climate risk management strategies, they needed a deeper understanding of index insurance, the benefits and potential shortcomings of satellite-based rainfall indices, and the relevant climate science (Sharoff et al. 2012). Farmers in particular wanted to learn more about index insurance so that they could make informed decisions on whether it was an appropriate tool for them, how it could be tailored to better meet their needs and how to take advantage of the productive opportunities that it could create. It was also essential to create a mechanism through which all stakeholders (including farmers) could provide their input, be involved in project decision-making and participate in a collaborative demand-driven process for index design.

To enable this new understanding, IRI created an index insurance capacity development process built on three main components: a) trainings regarding index insurance, climate risk management and climate information; b) facilitation of information sharing; and c) collaborative development and tailoring of materials for different audiences, so that local partners can build their own capacity development, design and implementation processes. This three-pronged approach is a critical component of the climate services that IRI has helped develop in East Africa. For additional details on climate services in the East Africa context, see Bridging Critical Gaps in Climate Services and Applications in Africa (Dinku et al. 2014).

Based on these three components, IRI has been developing educational and training activities for local partners in the R4 project, who lead the on-the-ground implementation of index insurance and climate risk management activities. These trainings, usually in the form of workshops, have acted as a foundation for project technical capacity development. Presentations, hands-on exercises using real case study data, interactive games, reading materials, and group discussions are used to demonstrate the main concepts of index insurance and get feedback on issues such as farmers' vulnerabilities, local historic climate information, cropping cycles, farming decisions and input for draft indices. This process helps ensure that indices address the specific climate and production risks that each region faces.

In addition, IRI has been collaborating with local partners to develop participatory processes and capacity development materials that are used to engage farmers, allowing the end clients to be part of the index design process. Local input on the development of this material ensures that it is framed within a context to which local farmers can relate.

Project partners use this material to facilitate communication and outreach with farmers. Using this process, a design team comprised of farmer community members is formed. This team learns about index insurance and provides valuable information for designing and refining an index, such as defining when the rains are the most important, identification of historically "bad" and "good" years, primary crops and local risk management strategies. Interactive games and discussions are often developed for local communities, allowing the farmers to play through scenarios, test out different decisions and experience possible outcomes. During later phases of the project, the capacity development material enables further two-way information sharing. Project partners inform the design team what a draft index may look like and farmers are given the opportunity to provide feedback. These scenarios also help farmers make more informed decisions about purchasing index insurance.

By giving everyone a seat at the table, the result is an insurance index that is very flexible and easily tailored to the requests of each farmer community in Ethiopia. The use and unique design of this capacity development process plays a significant role in helping to overcome traditional barriers to index insurance implementation (Hellmuth et al. 2009), such as lack of farmer understanding of, and trust in, the products, by having community outreach programs and by generating community involvement and feedback in the design process.

The success of the program shows what developing strong relationships and local capacity can do. R4 Ethiopia has scaled up from 200 farmer households in 2009 to more than 19,000 in 2012 (Oxfam 2013). In October and November of 2012, satellite data triggered payouts to more than 12,000 farms in Ethiopia, putting this type of index insurance and the scaling up process to its largest test to date (IRI, 2012).

Building on the R4 Ethiopia experience, IRI has continued to refine its capacity development process, addressing similar needs seen in other projects around the world. Materials are now being collaboratively developed and used in local languages in countries including Indonesia, Kenya, Dominican Republic, Colombia and Senegal.

\section{Conclusion}

The capacity development efforts and activities described here showcase both the common and targeted methods that IRI employs to facilitate the translation of climate information into climate knowledge for society. These methods are based on 18 years of experience conducting and evaluating trainings and developing curricula for end users in agriculture, public health, water and other key development sectors. While individual efforts are geared toward different audiences and develop a different type of capacity and knowledge, together they all treat end users as collaborators who have equal footing 
with IRI researchers. The examples we highlight above also demonstrate that training information providers and decision makers to better understand, use and manage climate information is particularly effective when the trainings are tailored to meet local needs and the users are involved from an early stage. Finally, the examples highlight the evolution of IRI's capacity development role, moving from provider to partner.

Trainings have been an important component of the IRI since its inception. While the IRI started with training users, it has now progressed to training future trainers as well. In essence, IRI has transitioned from building capacity to developing capacity. In this way, IRI has produced a larger cadre of trainers pursuing positive outcomes in today's increasingly climate-sensitive world.

\section{Endnotes}

${ }^{a}$ Mercosur Region (including Uruguay, Paraguay, Brazil and Argentina) and the Andean region (including Colombia, Ecuador, Peru, Bolivia, Chile and Venezuela).

${ }^{\mathrm{b}}$ The R4 Rural Resilience Initiative is lead by Oxfam America (OA) and the World Food Programme (WFP). For more information go to http://www.oxfamamerica.org/ explore/research-publications/copy_of_r4-rural-resilienceinitiative- $2 /$.

${ }^{\mathrm{C}}$ In addition to OA and the WFP, the R4 Ethiopia (HARITA) project's network of partners includes the Relief Society of Tigray (REST) Ethiopian farmers, Nyala Insurance Share Company, Africa Insurance Company, Dedebit Credit and Savings Institution (DECSI), Mekelle University, the government of Ethiopia, IRI, and Swiss Re.

\footnotetext{
Abbreviations

AFENET: African field epidemiology network; CDC: Center for disease control; CIESIN: Center for international earth science information network; CIPHA: Climate information for public health action; CIPHAN: Climate information for public health action network; CIPH: Climate information for public health; COF: Climate outlook forum; CPT: Climate predictability tool; ENSO: El Niño-Southern oscillation; GIS: Geographical information systems; HARITA: Horn of Africa risk transfer for adaptation; IAl: Inter-America Institute for global change; IRI: International Research Institute for Climate and Society; MSPH: Mailman school of public health; NMA: National meteorological agencies; NOAA: National Oceanic and Atmospheric Administration; OA: Oxfam America; PAHO: Pan American Health Organization; REST: Relief Society of Tigray; TEPHINET: Training programs in epidemiology and public health interventions; WMO: World Meteorological Organization.
}

\section{Competing interests}

The authors declare that they have no competing interest.

\section{Authors' contributions}

$A B$ : participated in the conceptualization of the manuscript and drafted parts of the manuscript. AC: participated in the design and editing of the manuscript. GM: participated in the design and coordination of manuscript, writing and editing the manuscript. JS, participated in the conceptualization, writing and editing of the manuscript. $C T$, participated in the conceptualization, writing and editing of the manuscript. All authors read and approved the final manuscript.

\section{Authors' information}

Anthony G. Barnston as Chief Forecaster oversees the production and scheduled issuance of a range of IRI climate forecast products. He participates in implementation of improved methods and tools to enhance the quality and content of the forecasts. He seeks to engage the user community on forecast interpretation and use, including the national and international media. He provides training and capacity building on aspects of climate forecasting for visiting scientists, students, and forecasters at national meteorological centers abroad. He designed and teaches the statistics portion of a core quantitative course in the curriculum of the Climate and Society masters program at Columbia University- a course relating climate to decision making in the climate-sensitive components of society. He has published on research studies involving mainly empirical climate prediction methods over the last 30 years.

Ashley Curtis coordinates the climate group and training activities at IRI and contributes to research and outreach efforts. Actively involved with IRI's partnership with the International Federation of the Red Cross and Red Crescent Societies, Curtis communicates and contextualizes climate and forecast information that humanitarian decision makers can then use to improve preparedness for weather and climate related disasters. She holds a M.A. in Environmental Science and Policy from Clark University and a B.A. in Biology from Bard College.

Gilma Mantilla is a medical doctor by training with over 20 years of public health experience on designing and implementing public health policy; health promotion and disease control programs and infectious disease surveillance and control systems. In the last seven years with extensive engagement in policy processes involving the development of effective demand for climate information including the implementation of innovative tools and protocols for creation, integration and dissemination of knowledge and information related with climate and public health. Education and training have been key components of her work; she has organized training courses, developed curriculum and trained international public health staff in public health management, public health policy and the use of climate information to improve decisions. Gilma Mantilla was previously the team leader on climate and public health training at IRI. Currently she is a Researher at the Centro de Estudios e Investifacion en Salud.

Jessica Sharoff is a Research Staff Associate at IRI. She works on a variety of projects, which focus on aiding decision-makers and humanitarian organizations in improving access, understanding and use of climate information. Sharoff leads capacity building activities for the index insurance team in East Africa and Southeast Asia and contributes to collaborative projects with the CGIAR Research Program on Climate Change, Agriculture and Food Security and International Federation of Red Cross and Red Crescent Societies in these regions. Prior to joining IRI, Sharoff worked with the Joint Oceanographic Institutions, the Center for Research on Environmental Decisions, and the Red Cross/Red Crescent Climate Centre. She holds a M.A. in Climate and Society from Columbia University and a B.S. in Science of Earth Systems from Cornell University. Cynthia Thomson is the Assistant Director of the M.A. in Climate and Society at Columbia University. Prior to her current position, Thomson worked with the Red Cross/Red Crescent Climate Centre on incorporating climate forecasts into disaster risk reduction practices in the pacific region. Thomson has an M.A. in Climate and Society from Columbia University and a B.A. in Geography from the University of Ottawa.

\section{Acknowledgements}

We would like to thank lead funders, including NOAA, USAID, WMO, OXFAM America, WHO, PAHO, UN ILO, SERVIR, R4, Swiss Re and IAI for financial support to the trainings identified in the paper along with the engaged interaction of many regional partners. We also acknowledge the scientific and technical support of many IRI staff that have contributed to the design and implementation of the trainings over the last decade.

Responsible editor: Ghassem Asrar.

\section{Author details}

${ }^{1}$ Centro de Estudios e Investigacion en Salud, Cra. 7 B No. 123, Bogota, Colombia. ${ }^{2}$ The International Research Institute for Climate and Society (IRI), The Earth Institute, Columbia University, Lamont Campus, 61 Route 9, Monell Building, Palisades, NY 10964-8000, USA. 


\section{References}

(2012) IRI press release: Poor Ethiopian Farmers Receive "Unprecedented" Insurance Payouts. [http://iri.columbia.edu/docs/features/2012_spotlight_features/ poor_ethiopian_farmers_receive_unprecedented_insurance_payout.html]

CHIPH Newsletter (2008). [http://iri.columbia.edu/our-expertise/public-health/ ciphnews]

Climate information for Public Health Action Network (2009). [http://ciphan.iri. columbia.edu/]

The downloadable Climate Predictability Tool. [http://iri.columbia.edu/ourexpertise/climate/tools/cpt/]

Bank W (2011) Weather Index Insurance for Agriculture: Guidance for Development Practitioners. Washington DC

Cibrelus L, Mantilla G (2009) Summary of the Climate Information for Public Health Training Course. [http://iri.columbia.edu/publications/id=909]

Cibrelus L, Mantilla G (2010) Climate Information for Public Health: A Curriculum for Best Practices. [http://iri.columbia.edu/resources/publications/pub_id/1044/]

Cibrelus L, Raholijao N, Raoelina Y, Rakoarivony MC, Tuseo L, Cousin R, Kootval H (2010) Synthesis report on Training Courses on the Use of Climate Information for Public Health in Madagascar. [http://iri.columbia.edu/ publications/id=1034]

Connor SJ, Omumbo J, Green C, Da S, Mantilla G, Delacollette C, Hales S, Rogers D, Thomson M (2010) Health and Climate - Needs. Procedia Environ Sci 1:27-36

Del Corral J, Blumenthal B, Mantilla G, Ceccato P, Connor S, Thomson M (2012) Climate information for public health: the role of the IRI climate data library in an integrated knowledge system. Geospat Health 6(3):15-24

Dinku T, Block P, Sharoff J, Hailemariam K, Osgood D, del Corral J, Cousin R, Thomson M (2014) Bridging Critical Gaps in Climate Services and Applications in Africa. Earth Perspect 1:15

Hazell P, Anderson J, Balzer N, Clemmensen A, Hess U, Rispoli F (2010) The Potential for scale and sustainability in weather index insurance for agriculture and rural livelihoods. IFAD, Rome

Hellmuth ME, Osgood DE, Hess U, Moorhead A, Bhojwani H (2009) Index insurance and climate risk: Prospects for development and disaster management. Climate and Society No. 2. International Research Institute for Climate and Society (IRI). Columbia University, New York

Korecha D, Barnston AG (2007) Predictability of June-September rainfall in Ethiopia. Mon Weather Rev 135:628-650

Lowe R, Mantilla G, Mendiola L (2010) Technical Report on Summer Institute on Climate Information for Public Health. [http://iri.columbia.edu/publications/id=1123]

Mantilla G, Lustig A (2012) Informe Tecnico Curso Andino en Clima y Salud. [http://iri.columbia.edu/publications/id=1181]

Mantilla G, Stanton M, Clbrelus L (2010) Technical Report on Summer Institute on Climate Information for Public Health. [http://iri.columbia.edu/publications/id=1011]

Mantilla G, Vaughan C, Ohiara M, Ciganda C (2011) Informe Tecnico del Instituto de Capacitación en Clima y Salud. Mercosur [http://iri.columbia.edu/ publications/id=1137]

Mason SJ, Goddard L, Graham NE, Yulaeva E, Sun L, Arkin PA (1999) The IRI seasonal climate prediction system and the 1997/98 El Niño event. Bull Am Meteorol Soc 80:1853-1873

Oxfam (2013) R4 Rural Resilience Initiative. Oxfam America. Quarterly Report., in press

Schwank O, Steinemann M, Bhojwani H, Holthaus E, Norton M, Osgood D, Sharoff J, Bresch D, Spiegel A (2010) Insurance as an Adaptation Option Under UNFCCC: Background Paper; Swiss Federal Office for the Environment

Sharoff J, Legesse RD, McCarney G, Norton M (2012) R4 Rural Resilience Initiative in Ethiopia; Climate Services Partnership. [http://www.climate-services.org/ content/r4-rural-resilience-initiative-ethiopia]

Teka H, Woyessa A, Jima D, Mantilla G (2009) Report on Training of Health Professionals on Climate and Health. [http://iri.columbia.edu/publications/id=981]

\section{doi:10.1186/2194-6434-1-21}

Cite this article as: Mantilla et al: Capacity development through the sharing of climate information with diverse user communities. Earth Perspectives 2014 1:21.

\section{Submit your manuscript to a SpringerOpen ${ }^{\odot}$ journal and benefit from:}

- Convenient online submission

- Rigorous peer review

- Immediate publication on acceptance

- Open access: articles freely available online

- High visibility within the field

- Retaining the copyright to your article

Submit your next manuscript at $\gg$ springeropen.com 